\title{
Peronismo e cultura: o Primeiro Congresso de Bibliotecas Populares da Província de Buenos Aires (1949)
}

\author{
Paulo Renato da Silva
}

\author{
Introdução: Peronismo e Historiografia
}

\begin{abstract}
Tenho falado de uma política cultural e posso provar, com plena confiança, que o governo tem uma política cultural, desenvolve uma política cultural, e que o Congresso de Bibliotecas Populares, independentemente de seus resultados, é a representação de uma verdadeira política educacional e cultural. Julio Cesar Avanza, Ministro da Educação da Província de Buenos Aires, $1951^{1}$
\end{abstract}

Entre as décadas de 1960 e 1980, os estudos sobre os dois primeiros mandatos presidenciais de Juan Domingo Perón (1946-1955) priorizaram questôes referentes à organização política dos trabalhadores argentinos em termos partidários e sindicais. Trabalhos como os de Gino Germani, Miguel Murmis e Juan Carlos Portantiero, e de Daniel James, dentre inúmeros outros, mostram o predomínio dessas questôes nos principais estudos sobre o peronismo.

Apesar das divergências entre os autores, desde o começo, a historiografia ressalta que o governo de Perón não controlou totalmente o movimento operário. Germani considera que o peronismo não foi sustentado pelos imigrantes europeus, há mais tempo em Buenos Aires e mais experientes no movimento operário do que os migrantes internos, os quais, segundo o autor, formaram a principal base social de Perón. Para Germani, a inexperiência política e sindical dos migrantes fez com que fossem manipulados pelo governo de Perón. Teriam vivido como integração a mobilização oferecida pelo peronismo:

O peronismo constituiu, sem dúvida, um caso de manipulação bem sucedido, já que conseguiu proporcionar uma participação efetiva das camadas mobilizadas, apesar de, como é óbvio, abster-se de reformas sociais ou mantê-las dentro dos limites aceitáveis pelos grupos sociais e econômicos mais poderosos. ${ }^{2}$

Miguel Murmis e Juan Carlos Portantiero, por sua vez, defendem que o reformismo peronista já era uma tendência do movimento operário argentino desde o começo da década de 1930. Segundo os autores, a crise econômica internacional de 1929 e a repressão ao movimento operário fortaleceram os líderes sindicais que pregavam a negociação com os patrōes e o Estado. Assim, ao invés de manipulação, como propõe Germani, destacam que houve uma aliança de classes nas origens do peronismo. Em outras palavras, conferem autonomia ao movimento operário na adesão ao peronismo. Entretanto, essa autonomia teria sido perdida em uma etapa seguinte. "Não haveria, nesse sentido, uma dissolução da autonomia em favor da heteronomia operária, no momento inicial do peronismo na Argentina, mas, em todo caso, em uma etapa posterior". ${ }^{3}$

Já Daniel James destacou-se ao apontar as resistências dos trabalhadores ao peronismo, inclusive daqueles que compunham sua base social. O autor enfatiza, por exemplo, a dificuldade dos líderes sindicais peronistas em controlar a "violência" de suas bases e em fazê-las aceitar planos de aumento da produtividade instituídos pelo governo de Perón.

Ainda que destaquem fissuras, os autores são unânimes em dividir a história do movimento operário argentino em antes e depois do peronismo. O controle do governo de Perón teria predominado sobre os desvios dos trabalhadores. Como mencionamos, Germani ressalta a expressiva adesão ao peronismo entre 
os migrantes. Murmis e Portantiero defendem que o governo de Perón conseguiu desarticular a autonomia do movimento operário. Daniel James, inclusive, no título de seu livro mais conhecido sobre o assunto, Resistencia e integración: el peronismo y la clase trabajadora argentina (1946-1976), já antecipa que a relação dos trabalhadores com o peronismo foi marcada por resistências, mas também pela integração:

O Estado peronista, sem dúvida, obteve um sucesso considerável no controle da classe trabalhadora, tanto social quanto politicamente e, embora a luta de classes não tenha sido, de forma alguma, abolida, assim como não se atingiu o idílio da harmonia social retratado pela propaganda oficial, as relações entre capital e trabalho melhoraram consideravelmente. A temida vingança dos sans-culotte de Buenos Aires, aparentemente anunciada pela turbulência social e política de 1945-1946, não se concretizou. Várias razões podem ser aventadas para explicar este sucesso. Uma delas foi a capacidade da classe trabalhadora para satisfazer suas aspiraçōes materiais, dentro dos parâmetros oferecidos pelo Estado; outra, o prestígio pessoal de Perón. Também é necessário considerar a habilidade do Estado e de seu aparato cultural, político e ideológico, para promover e incutir noçôes de harmonia e interesses comuns entre as classes. ${ }^{4}$

As relações entre o governo de Perón e o movimento operário argentino continuam chamando a atenção dos pesquisadores. Porém, da década de 1990 em diante, é perceptível uma mudança quanto ao objeto que tem norteado os debates: especialistas têm destacado como a cultura também teve um lugar central no projeto político peronista. Tal mudança não representa necessariamente um abandono da questão operária, mas procura aproximar as duas preocupações, ou seja, procura pensar os trabalhadores inseridos nos debates culturais do período, muitos dos quais promovidos, ou apoiados, pelo próprio governo de Perón e aliados. Exemplo disso encontramos no Primeiro Congresso de Bibliotecas Populares da Província de Buenos Aires, como detalharemos a seguir. O governo de Perón pretendia transformar amplamente a sociedade, formar um "novo" homem a partir da difusão de valores morais, populares e nacionais. Nas palavras de Eva Perón, há "uma conduta pessoal e uma conduta peronista; ambas não são mais do que o cumprimento do dever, diário e contínuo, pelo bem da Pátria, do Partido e de seu Chefe". ${ }^{5}$ Para o governo, a política partidária, sindical e social era indissociável da cultural. A consolidação do apoio dos trabalhadores passaria por todas essas esferas. Daí a preocupação do governo em controlar instituiçôes educacionais e a produção cultural.

Inicialmente, porém, a cultura parece ter sido enfocada pela historiografia sobre o peronismo apenas para ressaltar o forte apoio que Perón teria recebido dos trabalhadores. Conforme a citação acima, James defende que o "aparato cultural, político e ideológico" do Estado peronista habilmente incutiu a harmonia de classes nos trabalhadores.

Alberto Círia, em Política y cultura popular: la Argentina peronista (1946-1955), destacou que a apropriação da História nacional, da "cultura popular" e de espaços públicos pelo peronismo foi fundamental para consolidar o apoio dos trabalhadores. Trata-se de uma ideia recorrente, que se embasa em vários exemplos. Perón se apresentava como um continuador de San Martín; após a independência política no século XIX, o presidente divulgava ter consolidado, no XX, a soberania econômica do país. Além disso, o governo elegeu as praças como um dos principais lugares de encontro com os setores populares, um modo de se apropriar da tradição democrática surgida a partir da Grécia antiga. ${ }^{6} \mathrm{O}$ presidente e a primeira-dama, Evita, ainda atribuíram sentido positivo a palavras antes pejorativas usadas para designar os setores populares, como "descamisados" e "grasitas". 7 Para mencionar apenas mais um exemplo, muito conhecido, o peronismo se apropriou de lugares tradicionalmente de elite como o Teatro Colón de Buenos Aires, no qual passou a promover festivais populares e reuniōes partidárias e sindicais. De acordo com Círia, exemplos como esses teriam representado simbolicamente para os trabalhadores as conquistas obtidas na esfera social e teriam ajudado a ressaltar a ruptura que o governo de Perón afirmava empreender na história do país.

Outros autores, no entanto, apresentam uma perspectiva um tanto distinta a respeito do papel da cultura no governo de Perón. Mariano Plotkin e Maria Helena Rolim Capelato destacam que a propa- 
ganda política e a produção cultural são instrumentos de controle social. Contudo, Plotkin considera que a preocupação demasiada do governo de Perón com a propaganda política e a produção cultural demonstra, justamente, a dificuldade para se alcançar um consenso, uma harmonia social. Capelato observa que, durante o governo de Perón, por exemplo, os filmes e programas de rádio que reproduziam mensagens oficiais costumavam ter menor bilheteria e audiência.

Ainda vale comentar os trabalhos de Flavia Fiorucci, nos quais se detém sobre os esforços do governo de Perón para conquistar o apoio de intelectuais. Segundo a autora, dentre outros pontos, o expressivo mercado editorial argentino diminuía a dependência dos intelectuais em relação ao Estado, o que teria representado um empecilho para o peronismo atrair intelectuais, sobretudo os já reconhecidos, ao contrário do que teria acontecido no Brasil, durante os governos de Getúlio Vargas. Dessa maneira, além de uma mudança de objeto, é perceptível um novo enfoque em curso: se por um lado o peronismo teria conseguido mudar a estrutura partidário-sindical do país, no plano cultural não teria alcançado o mesmo êxito.

A partir dos Anais do Primeiro Congresso de Bibliotecas Populares da Província de Buenos Aires (1949), publicados em 1951, nosso objetivo é destacar alguns dos principais pontos da política cultural do governo de Perón, ou seja, suas propostas, divergências e críticas recebidas.

Michel de Certeau sintetiza que o objetivo de toda política cultural é transformar comportamentos. Assim, a política e a produção cultural peronista possibilitam ter acesso a uma dimensão conflitiva distinta daquela explorada pela historiografia no âmbito partidário-sindical.

A análise dos Anais do Congresso aponta para o destacado por Plotkin, isto é, a dificuldade de Perón em obter um consenso. Seu governo se deparou com diferentes pensamentos, hábitos e tradiçōes, os quais nem sempre convergiam com os valores populares e nacionais que dizia representar. Resumidamente, para Perón e Evita, o nacional e o popular estavam ligados à matriz hispânico-católica e rural deixada pela colonização: "Espanha, Nossa Mãe. Filha eterna da imortal Roma, herdeira dileta de Atenas, a Graciosa, e de Esparta, a Forte!... ${ }^{8}$ Contudo, o presidente e a primeira-dama também se depararam com variadas concepções sobre o que seria o popular e o nacional.

Essa complexidade da sociedade argentina vinha de um processo de modernização que se acentuou já a partir da década de 1920. A imigração estrangeira, a industrialização, a urbanização e a migração interna teriam tornado menos precisos conceitos como nacional, popular e tradicional, centrais no discurso cultural de Perón e Evita. Segundo Beatriz Sarlo, formou-se na Argentina uma "cultura de mescla": "[nela] coexistem elementos defensivos e residuais junto a programas renovadores (...). A mescla é um dos traços menos transitórios da cultura argentina".

Entretanto, a historiografia sobre o peronismo ainda não incorporou efetivamente em seus debates esse processo de modernização examinado por Beatriz Sarlo. No caso do peronismo, permanece a relação comumente estabelecida entre os setores populares e as tradições, criticada por autores como Néstor García Canclini. "A bibliografia sobre cultura costuma supor que existe (...) um destino fatídico dos populares que os arraiga às tradições". ${ }^{10} \mathrm{~A}$ análise dos Anais do Congresso permite afirmar que uma das maiores dificuldades do governo de Perón parece ter sido justamente essa, "arraigar os populares às tradiçōes".

\section{O Primeiro Congresso de Bibliotecas Populares da Província de Buenos Aires}

O Congresso foi realizado entre 15 e 18 de dezembro de 1949, em La Plata, capital da Província. A realização do Congresso durante a primeira presidência de Perón (1946-1952) indica que as medidas sociais e trabalhistas que popularizaram o peronismo vieram acompanhadas de ações na esfera cultural. Portanto, não foram preocupações dissociadas. Vale assinalar, contudo, que a imagem de que o peronismo se preocupou inicialmente com questôes sociais e trabalhistas e, apenas depois, com as culturais foi difundida inclusive por simpatizantes do governo de Perón. Em artigo favorável à expropriação do jornal liberal e antiperonista La Prensa pelo governo, assim se pronunciou, em 1951, a revista cultural nacionalista Substancia, de Concepción del Uruguay, Província de Entre Ríos: 
Já dissemos anteriormente que, pressionada pelos problemas fundamentais e inadiáveis da libertação econômica dos oprimidos, a Revolução não podia pensar muito na cultura. Com La Prensa popular, o Justicialismo começará a provar que a Revolução também é cultura e pensamento. ${ }^{11}$

O Congresso contou com a participação de autoridades provinciais como Julio Cesar Avanza, Ministro da Educação da Província de Buenos Aires (citado na epígrafe), e Jose Cafasso, Subsecretário Interino de Cultura. Perón e Domingo Alfredo Mercante (1898-1976), governador da Província de Buenos Aires (1946-1952), não estiveram presentes. Entretanto, quando os discursos e as propostas do encontro foram publicados, em 1951, o livro foi aberto com desenhos do rosto de ambos, acompanhados de mensagens sobre a importância da cultura para o peronismo. A mensagem atribuída a Perón frisa a relação entre a política social e a cultural de seu governo:

Nossa política social (...) tem como objetivo, acima de tudo, a mudança de uma concepção materialista da vida, para uma exaltação dos valores espirituais. Por esse motivo, pretendemos elevar a cultura social. O governo argentino não deve poupar esforços, nem sacrifícios de qualquer tipo, para fazer chegar, a todos os âmbitos da nação, os ensinamentos adequados para engrandecer a cultura de seus habitantes. ${ }^{12}$

Desse modo, o Congresso não pode ser visto de forma restrita, como uma iniciativa limitada à Província. Vale ressaltar que a Província de Buenos Aires era - e continua sendo - a mais populosa do país. Além disso, Mercante e Perón ainda não tinham rompido politicamente quando o Congresso foi realizado ${ }^{13}$. Tanto não foi uma iniciativa restrita que, entre 9 e 12 de outubro do ano anterior, tinha sido realizado, em Córdoba, o Primeiro Congresso Nacional de Bibliotecas Populares, no qual teria surgido a ideia de se realizar o congresso provincial.

Além de autoridades, houve a participação de duzentos e oitenta e sete representantes de bibliotecas populares da Província de Buenos Aires e, inclusive, de outras regiōes do país. Certamente colaborou para que o número de congressistas fosse expressivo a ajuda econômica dada pelo governo provincial: os representantes de bibliotecas situadas a mais de sessenta quilômetros de La Plata tiveram passagens e estadia pagas. Os representantes formaram comissões encarregadas de discutir temas previamente determinados.

O evento pretendia não apenas aproximar as bibliotecas populares entre si, mas também "tornar mais estreitos os vínculos que as unem (...) com os órgãos oficiais afins, para (...) coordenar melhor a ação que desenvolvem em benefício da cultura e da educação do povo". ${ }^{14}$ Tratava-se, portanto, de uma tentativa de apropriação de um dos principais legados da tradição liberal argentina: a criação e expansão das bibliotecas populares. ${ }^{15} \mathrm{O}$ presidente do Congresso, o capitão Luciano C. Pessacq, citou Sarmiento na abertura. "os que virão depois encontrarão, um pouco mais aplainado, o caminho iniciado por Sarmiento, e que conduz a uma Argentina grande, imensamente grande". ${ }^{16}$ A Mesa Diretora rendeu, inclusive, uma homenagem a Sarmiento, sob a inspiração de quem o Congresso teria transcorrido. ${ }^{17} \mathrm{~A}$ programação indica a tentativa do peronismo de se apropriar da tradição liberal argentina, ou seja, de conciliar os legados de nomes como Sarmiento e San Martín com as realizações do governo de Perón:

Dia 17:

12 hs.: Almoço oferecido pelo Grupo de Bibliotecas Populares na Associação Sarmiento.

16 hs.: Visita ao Parque dos Direitos dos Idosos na localidade de Pereyra (condicional).

18 hs.: Oferenda de flores ao libertador General San Martín. ${ }^{18}$

Foi apresentado um projeto de lei para regulamentar o funcionamento das bibliotecas populares na Província de Buenos Aires. O projeto de lei apresenta pontos que demonstram a intenção do governo provincial em intervir nas bibliotecas. $\mathrm{O}$ apoio do governo à fundação, manutenção e organização das bibliotecas deveria vir acompanhado de contrapartidas.

Uma das funções da Direção Geral de Bibliotecas Populares seria apurar o emprego dos recursos, tendo em vista garantir o "normal funcionamento" ${ }^{19}$ das bibliotecas. Aliás, para que as bibliotecas fossem reconhecidas pelo governo, seria preciso aceitar "a fiscalização do emprego dos recursos e elementos providos pela Direção Geral”. ${ }^{20}$ 
Para serem reconhecidas, as bibliotecas também não poderiam "servir como instrumento de propaganda política ou religiosa". A exigência não era casual, pois, durante a Segunda Guerra Mundial (1939-1945), as bibliotecas populares se destacaram como centros do pensamento liberal e socialista na crítica ao nacionalismo autoritário. ${ }^{21}$

A quantidade de recursos destinados às bibliotecas variaria de acordo com o tamanho dos acervos. Entretanto, como indica o trecho a seguir, a mudança de categoria seria pautada por critérios menos objetivos. Acreditamos que, na prática, seriam utilizados critérios políticos:

A promoção para uma categoria superior poderá ser adiada pela Direção Geral, se a biblioteca subvencionada não cumprir seu serviço, de acordo com a importância de seu acervo bibliográfico. A Direção Geral, após examinar o trabalho realizado por cada biblioteca, poderá fazer contribuiçôes especiais às entidades reconhecidas, através de resolução devidamente fundamentada. ${ }^{22}$

A Direção Geral controlaria, inclusive, a formação técnica dos funcionários, através da criação de uma escola de bibliotecários. A ajuda econômica para que os representantes das bibliotecas populares pudessem participar do encontro em La Plata demonstra a intenção do governo provincial em envolver amplamente as instituiçóes nesse projeto de lei.

No entanto, essa tentativa de se apropriar da tradição liberal através das bibliotecas populares não era um processo simples. Ao abrir a assembleia que elegeria as autoridades do Congresso, Cafasso procurou frisar que o governo não interferiria nas atividades, respeitando, assim, a autonomia legalmente garantida às bibliotecas populares do país:

Embora a Subsecretária de Cultura, através da Direção Geral de Bibliotecas, seja responsável por todas as questôes relativas à organização e à programação do Congresso, minha presença nesta cerimônia, obedece apenas ao propósito de presidir a sessão preparatória até que sejam constituídas as autoridades definitivas, o que os próprios congressistas irão anunciar logo em seguida. ${ }^{23}$

Preocupação semelhante à de Cafasso demonstrou Julio Cesar Avanza na abertura do encontro. O Ministro da Educação provincial fez uma distinção entre intervencionismo e colaboração estatal: "direção e incentivo, (...) de modo algum, destinados a sufocar a expressão autêntica desses órgãos [as bibliotecas populares]. Não pretendo fundamentar, aqui, a injustiça de um intervencionismo estatal". ${ }^{24}$

Essa preocupação demonstrada por membros do governo que estavam à frente do Congresso decorreu de uma pressão que se observa entre os participantes. A Comissão VII, em seu quarto despacho, declarou que "as Bibliotecas Populares, como representam uma criação da comunidade, devem conservar a liberdade de expressão e uma atitude de crítica construtiva em relação a todos os problemas da cultura popular" ${ }^{25}$

Como destacamos, "coordenar melhor a educação do povo" era um dos propósitos do evento. Apesar do discurso valorativo quanto à cultura popular, existiram divergências sobre o que seria esta cultura popular e o seu papel no peronismo. De qualquer maneira, predominou a visão de que a cultura popular precisaria ser transformada, principalmente através do acesso dos setores populares à cultura letrada. Pessacq destacou que deveria ser buscada "a aliança entre o livro e o povo" ${ }^{26}$ Logo, a cultura popular, como base do peronismo, apareceu no congresso como um projeto a ser realizado, não como uma essência, como algo já existente que apenas deveria ser resgatado e valorizado.

$\mathrm{Na}$ abertura, Cafasso destacou a necessidade de se "lutar contra o obscurantismo e intensificar a cultura entre as massas populares". ${ }^{27}$ No encerramento, Cafasso mencionou o trabalho e os "valores nacionais" como os elementos mais importantes a serem estimulados entre os setores populares. Havia, portanto, um discurso normativo quanto à cultura popular. No encerramento, Cafasso concluiu que "não existe cultura sem ordem, e que não é possível alcançar essa fisionomia espiritual, a que todos nós aspiramos, sem essa harmonia vital que se enraíza fortemente na autêntica essência nacional, e dela se nutre" ${ }^{28}$ 
Ao falar em autêntica essência nacional, Cafasso referiu-se indiretamente a uma essência que não seria nacional, apesar de assim se apresentar. Observamos uma diferenciação semelhante no discurso de Avanza, quando se referiu à cultura popular: "essa comunhão de todos os argentinos, nunca [é] tão fecunda e nunca, tão transcendente, como quando se estabelece na cultura do povo, quando se estabelece na verdadeira cultura popular". ${ }^{29}$ Essas distinçôes remetem ao que Andrés Bisso destaca em Acción Argentina: a existência de uma disputa entre liberais e antiliberais sobre o que seria o nacional e quem seria seu "verdadeiro" representante durante a Segunda Guerra Mundial. ${ }^{30}$ Acrescentamos a existência de uma disputa inerente ao que seria o popular e quem seria seu "verdadeiro" representante. ${ }^{31}$ Bisso não analisa a presidência de Perón, mas, ao que parece, essa disputa permaneceu durante o todo o governo peronista.

Analisando-se os discursos e as propostas, observamos que não existia consenso em torno do que seria o nacional e o popular, inclusive entre os participantes.

Dolis Nélida Bollini, representante da Biblioteca General San Martín, defendeu que a formação de uma cultura "humanista" e "integral" residia no acesso das crianças a "livros agradáveis, saudáveis, com episódios da vida nacional que lhes ensinem a amar a sua terra e que deem uma visão clara de sua pátria, tudo em harmonia com seus gostos e necessidades". ${ }^{32}$ Defendeu, ainda, que os livros eram instrumentos moralizantes contra os perigos existentes nas ruas. A primazia de temas nacionais também está presente na proposta de bibliotecas portáteis e circulantes feita por Leonor R. de Carpinetti, da Biblioteca Popular Sarmiento, de Lobería. A biblioteca, destinada a percorrer os núcleos rurais e suburbanos, deveria ter "romances escolhidos, de ambiente nacional". ${ }^{33} \mathrm{O}$ capitão Luciano C. Pessacq, por sua vez, apresentou um dos discursos mais enfaticamente nacionalistas:

Nossos intelectuais padecem de estrangeirismo, esquecendo-se do vernáculo. Existe uma ciência argentina, uma literatura argentina, uma história argentina, uma arte argentina. As bibliotecas populares devem atuar em função da argentinidade. Não é preciso, entretanto, desconhecer o imenso valor do gênio estrangeiro para enaltecer a importância dos nossos próprios valores. ${ }^{34}$

As propostas nacionalistas de Dolis Nélida Bollini, de Leonor R. Carpinetti e do capitão Luciano C. Pessacq encontraram variantes. A Comissão III defendeu que o conhecimento de autores argentinos deveria ser uma prioridade, mas também mencionou o "necessário conhecimento dos autores universais". ${ }^{35}$ Além disso, vale frisar que, para a comissão, dentre os autores argentinos, deveriam ser priorizados os autores locais e regionais.

Outra variante encontramos em Germán García, da Biblioteca Popular Asociación Bernardino Rivadavia, de Bahia Blanca. Em sua fala, a valorização de autores argentinos não está necessariamente relacionada a livros sobre temas argentinos:

Não estou me referindo especificamente à aquisição de obras de escritores argentinos, ou sobre temas argentinos, porque é óbvio que, em qualquer programa elaborado com inteligência, devem constar, em primeiro lugar, livros que estudem o país e a produção dos [escritores] que estão mais próximos de nós. ${ }^{36}$

Facundo N. Quiroga, presidente da Agrupação de Bibliotecas Populares de La Plata, ao falar sobre as bibliotecas infantis, defendeu que deveriam ser priorizados autores e temas iberoamericanos. ${ }^{37}$ Julio Cesar Avanza, apesar de ter destacado a necessidade de "fazer renascer as qualidades autênticas do ser nacional", considerou que "não podemos esquecer que formamos parte do mundo ocidental", ${ }^{38} \mathrm{em}$ relação ao qual distinguiu, sobretudo, a cultura hispânica.

Já em algumas propostas, não se nota qualquer hierarquia quanto à nacionalidade de autores e temas tratados. Guillermo Eiréz, da Biblioteca Florentino Ameghino, do "Club del Banco de la Pcia. de Buenos Aires", defendeu a publicação de um boletim quinzenal que se ocupasse "de informar às Bibliotecas, sobre o movimento bibliográfico nacional e estrangeiro". ${ }^{39}$ Luis J. Moro, da Biblioteca Suburbana $\mathrm{n}^{\circ} 28$ do "Club Sportivo Dock Sud", propôs a realização de ciclos de conferências que seriam divididas em "Clássicos argentinos", "Clássicos americanos", "Clássicos espanhóis" e "Clássicos universais" ${ }^{40}$ 
Notamos a ausência de uma hierarquia quanto à nacionalidade dos autores sugeridos, mesmo em propostas conservadoras como a de A. Branda, da Biblioteca Florentino Ameghino. De acordo com Branda, o principal objetivo da leitura era a formação moral, chegando a propor a constituição de "bibliotecas-arquivo" que guardassem "obras de fisiologia, livros que não atendam a uma finalidade textual, literatura pornográfica, com cenas inconvenientes à moral, etc." .41 Os bibliotecários deveriam, inclusive, observar a personalidade dos leitores regulares das bibliotecas para indicar-lhes leituras que proporcionassem "a cura de algum hábito pernicioso". ${ }^{42}$

Para as crianças, Branda recomendou Perrault, os irmãos Grimm e Schmid. Segundo Branda, esses autores conhecem amplamente a impressionabilidade das crianças e exaltam virtudes que todas deveriam admirar como o heroísmo, a generosidade, a gentileza e o arrojo por coisas nobres, dentre outras.

Aos adolescentes sugeriu Verne, Wells, D’Amicis, Smiles e adaptações de “obras clássicas”. Para os adolescentes existiriam menos opções e lamentou que muitos lessem "folhetins, literatura policial e livros de aventuras", ${ }^{43}$ os quais ofereceriam "emoções fáceis".

Para os adultos, destacou novamente Smiles, além de José Ingenieros e Sarmiento. Entre as obras de "caráter social ou ideológico", que enaltecessem "os ideais da nacionalidade", indicou, mais uma vez, Ingenieros, além de dois expoentes da tradição liberal argentina, Juan Bautista Alberdi e Sarmiento.

Assim, apesar de Branda destacar a necessidade de se difundir e priorizar as obras que exaltassem o "sentido da América" e o "amor por nossas coisas", como lendas e folclore, as suas referências e indicações de leitura são fortemente marcadas por autores estrangeiros não-hispânicos.

No próprio discurso nacionalista do capitão Luciano C. Pessacq encontramos elementos que ajudam a explicar essa variedade de propostas quanto a leituras que deveriam ser priorizadas. $\mathrm{O}$ capitão destaca que os temas argentinos ocupavam um lugar marginal na produção intelectual do país. Parece não se tratar de simples retórica, pois, para legitimar as obras com temas argentinos, iguala a qualidade delas aos "enormes valores da genialidade estrangeira". Em poucas palavras, o capitão usa a produção estrangeira para valorizar a nacional.

O parâmetro feito por Pessacq nos leva a destacar duas citações presentes em discursos do congresso. $\mathrm{Na}$ abertura, Julio C. Avanza mencionou o poeta e escritor francês Paul Valéry (1871-1945), ao defender que o desenvolvimento técnico não poderia predominar sobre a cultura e a natureza. No encerramento, Cafasso empregou palavras do filósofo espanhol José Ortega y Gasset (1883-1955) para falar sobre a importância da cultura. As citações se destacam, pois tanto Valéry como Ortega y Gasset foram colaboradores da revista Sur, considerada um dos principais núcleos antiperonistas. ${ }^{44}$ Ortega y Gasset, além de ter integrado o conselho estrangeiro da Sur, também teria sugerido o nome da revista. Além disso, Victoria Ocampo (1890-1979), proprietária da Sur, seguiu o modelo da Revista de Occidente de Ortega y Gasset. ${ }^{45}$ Após seis anos de governos considerados nacionalistas, autores e/ou temas argentinos não pareciam dar o tom no meio intelectual do país. ${ }^{46}$

Outra divergência que se observa entre os participantes refere-se à formação que deveria ser destinada aos setores populares, particularmente aos trabalhadores. Propostas que defenderam uma formação ampla, integral, dividiram espaço com propostas que sugeriram a constituição de bibliotecas especializadas, por exemplo, em conhecimentos técnicos e profissionalizantes.

Já mencionamos aqui a proposta de formação "integral" defendida por Dolis Nélida Bollini. A Biblioteca General Enrique Mosconi, da Y. P. F. de Ensenada, destacou que os bibliotecários deveriam conhecer os leitores para sugerir livros úteis, "tanto para seu[s] ofício[s], como para sua formação intelectual". ${ }^{47} \mathrm{O}$ capitão Luciano C. Pessacq, apesar de ter adotado uma das posiçôes mais nacionalistas, enalteceu a formação ampla que as bibliotecas populares ofereceriam ao "homem do povo":

O conceito de bibliotecário [guardador de libros, no original] foi substituído por um novo significado de cooperação social e, neste aspecto, as bibliotecas populares são, há algum tempo, as que dirigem seus esforços em busca dessa aproximação do homem do povo com o livro científico, com a divagação filosófica, com a magia da arte. ${ }^{48}$ 
Contrastando com esses participantes, Leonor R. de Carpinetti, na proposta de bibliotecas portáteis e circulantes para zonas rurais e suburbanas, observou que estas deveriam conter, além de romances de "ambiente nacional", livros sobre agricultura e pecuária. Rafael Roldán Vergés, da Biblioteca "Círculo Popular de Cultura”, de Zárate, defendeu que as bibliotecas populares deveriam ter seçôes técnicas destinadas a estudantes e operários e que o governo provincial priorizasse o fornecimento de livros técnicos às bibliotecas, principalmente àquelas já existentes em "escolas industriais, de artes e ofícios, de orientação profissional e similares". ${ }^{49}$ Tratava-se, portanto, de um acesso seletivo ao saber. Germán García foi mais explícito quanto a isso. "Uma biblioteca pequena, de vilarejo ou de bairro, não deve deixar-se seduzir pelo canto de sereia de obras luxuosas ou coleções que, ali, não seriam úteis nem para exibição". ${ }^{50}$

Cabe destacar, ainda, que houve diversas discussões referentes a aspectos técnicos e organizacionais. Neste âmbito, destacam-se a produção de catálogos atualizados, a reorganização de seções, o intercâmbio de materiais duplicados, o estabelecimento de serviços de preservação dos acervos, o empréstimo gratuito de livros a domicílio e a ampliação do horário de funcionamento, dentre outros. Ainda que não seja nosso propósito analisar essas questôes, elas mostram que a implantação da política cultural do governo de Perón passava pela resolução de problemas que iam muito além de divergências estritamente político-culturais.

No prólogo da publicação com os discursos e as propostas do Congresso são destacadas as medidas que já tinham sido implantadas entre 1949 e 1951. Dentre elas, a fundação de diversas bibliotecas, a criação de uma escola de bibliotecologia e de um instituto bibliotecológico, o estabelecimento de uma secretaria técnica de política cultural bibliotecária, a publicação de um boletim e a veiculação de um programa quinzenal na Rádio Província.

Contudo, ainda estava pendente a aprovação do referido projeto de lei apresentado no Congresso, o qual pretendia regulamentar o funcionamento das bibliotecas populares e possibilitava ao governo provincial intervir nas instituiçóes. Desconhecemos detalhes a respeito das opçóes políticas dos representantes das bibliotecas populares que participaram do congresso. De qualquer modo, a pendência quanto à aprovação do projeto de lei indica um quadro político complexo, não controlado facilmente pelo peronismo. Essa pendência e as divergências existentes durante o Congresso indicam limites enfrentados pelo governo de Perón na implantação de sua política cultural.

\section{Conclusão}

As interpretações sobre a ascensão e queda de Perón são múltiplas e têm merecido grandes esforços de historiadores, cientistas políticos, sociólogos e demais pesquisadores do tema. Porém, a questão da política e produção cultural não pode ser ignorada ou menosprezada nessas análises.

A legitimidade política do governo de Perón foi sustentada, mais do que geralmente se pensa, pela busca de um tênue equilíbrio entre a tradição liberal-democrática argentina e o projeto político-cultural peronista, como demonstra a tentativa do governo de se apropriar das bibliotecas populares e de ícones da tradição liberal-democrática como San Martín e Sarmiento. Perón, apesar do passado e do discurso antiliberal, assumiu a presidência em um momento marcado pelo fortalecimento dos ideais liberaldemocráticos, em virtude da vitória dos Aliados na Segunda Guerra Mundial. Daí a necessidade de se apropriar da tradição liberal-democrática argentina.

Cabe ressaltar que a preocupação do governo de Perón em se apropriar da tradição liberal-democrática do país está profundamente relacionada ao intento de consolidar sua política cultural. Além da intenção de formar um "homem peronista", marcado por valores morais, populares e nacionais, os esforços de Perón para estabelecer uma política cultural devem ser compreendidos como uma resposta à existência de instituições, de um mercado editorial expressivo e de meios de comunicação que veiculavam imagens, valores e pensamentos diversos. Além dos mencionados princípios liberal-democráticos, circulavam propostas culturais cosmopolitas e visões distintas sobre o nacional e o popular, inclu- 
sive, possivelmente, entre os próprios peronistas, tendo em vista a interferência do governo provincial e nacional na organização e realização do Congresso. Logo, o governo de Perón parece ter tido dificuldades para coordenar a diversidade de propostas existentes, não apenas na sociedade argentina, mas até mesmo na sua própria base social.

Outro dado importante demonstrado pelos Anais do Congresso é o papel do interior na consolidação do peronismo. Destacamos como, para Gino Germani, o discurso peronista foi especialmente apoiado por migrantes internos. Os imigrantes e seus descendentes, há mais tempo na "moderna" Buenos Aires, teriam resistido aos apelos peronistas. No entanto, considerando-se a variedade de propostas apresentadas, os Anais sugerem que a modernização vivida pela capital da Argentina também acontecia, ainda que em graus diferentes, no interior da Província, o que nos leva a questionar a visão tradicional do interior como o espaço privilegiado das tradições, o que explicaria, em parte, a ressonância do peronismo entre os migrantes internos e nas regiōes interioranas do país.

Finalmente, destacamos no início do artigo que, para o governo de Perón, a política partidária, sindical e social era indissociável da cultural. A julgar pela complexidade encontrada por Perón na esfera cultural, complexidade perceptível nos Anais do Congresso, cabe perguntar até que ponto seu governo foi realmente bem sucedido nas demais esferas, como costuma destacar a historiografia sobre o peronismo. Ou, pelo menos, cabe perguntar até que ponto Perón considerava que tinha obtido o apoio dos setores populares, conforme a historiografia destacaria nas décadas seguintes.

\section{Notas}

${ }^{1}$ Primer Congreso Provincial de Bibliotecas Populares. La Plata: Provincia de Buenos Aires; Ministerio de Educación; Dirección General de Bibliotecas, 1951. p. 25. Na Argentina, a palavra ministro também é usada para designar o que chamamos de secretários estaduais. No original: "He hablado de una política cultural y puedo demostrar con cabal confianza que el gobierno tiene una politica cultural, desarrolla una politica cultural, y que este Congreso de Bibliotecas Populares, cualquiera sean sus frutos, es la representación de una auténtica política educacional y cultural". [Tradução do Editor]

${ }^{2}$ GERMANI, Gino. Política e sociedade numa época de transição: da sociedade tradicional à sociedade de massas. São Paulo: Mestre Jou, 1973. p. 265.

${ }^{3}$ MURMIS, Miguel; PORTANTIERO, Juan Carlos. Estudos sobre as origens do peronismo. São Paulo: Brasiliense, 1973. p. 101. ${ }^{4}$ JAMES, Daniel. Resistencia e integración: el peronismo y la clase trabajadora argentina, 1946-1976. Buenos Aires: Siglo XXI Editores, 2005. p. 52. Grifos meus. No original: "El Estado peronista tuvo sin duda alguna considerable éxito en el control de la clase trabajadora, tanto social como políticamente, y si bien el conflicto de clases no fue en modo alguno abolido, así como no se cumplió el idilio de armonía social retratado por la propaganda oficial, las relaciones entre capital y trabajo por cierto mejoraron. La temida venganza del sans-culotte porteño, aparentemente presagiada por los tumultos sociales y políticos de 1945-46, no se materializó. Varias razones pueden proponerse para explicar ese éxito. Una fue la capacidad de la clase trabajadora para satisfacer sus aspiraciones materiales dentro de los parámetros ofrecidos por el Estado; otra, el prestígio personal de Perón. También es preciso tomar en consideración la habilidad del Estado y su aparato cultural, político e ideológico para promover e inculcar nociones de armonía e intereses comunes de las clases". [Tradução do Editor]

${ }_{5}^{5}$ PERÓN, E. Por qué soy peronista y las fuerzas espirituales del peronismo. Buenos Aires: C. S. Ediciones, 1996. p. XXIIXXIII. No original: “... una conducta personal y una conducta peronista; ambas no son sino el cumplimiento diario y continuo en bien de la Patria, del Partido y de su Jefe". [Tradução do Editor]

${ }^{6}$ Neste trabalho, empregamos a expressão "setores populares" no sentido proposto por Leandro Gutiérrez e Luis Alberto Romero em Sectores populares, cultura y política: Buenos Aires en la entreguerra. O conceito permite pensar os trabalhadores em esferas que vão além do processo produtivo, como a da produção e circulação cultural. Além disso, possibilita a inclusão de mulheres, crianças e idosos, à margem do processo produtivo, mas também alvos de distintos discursos políticos, particularmente do peronista.

${ }^{7}$ Segundo Sérgio Molina, tradutor de Santa Evita, de Tomás Eloy Martínez, “Grasa é, para o portenho com pretensões de distinção, toda e qualquer pessoa não polida à sua imagem e semelhança. Literalmente, a palavra significa graxa, sebo, gordura. Mas o tom carinhoso do diminutivo inverte o sinal: o que era desprezível passa a ser amado." (São Paulo: Companhia das Letras, 1997. p. 14). Evita empregou a palavra "grasitas", por exemplo, em seu "testamento político". "Dios sabe también que nunca he odiado a nadie por si mismo, no he combatido a nadie con maldad, sino por defender a mi pueblo, a mis obreros, a mis mujeres, a mis pobres "grasitas" a quienes nadie defendió jamás con más sinceridad que Perón y con más ardor que Evita". (El testamento. Cuadernos de Crisis, Buenos Aires, nº 7, s./d., p. 57). 
${ }^{8}$ PERÓN, Juan Domingo. Doctrina peronista. Buenos Aires: C. S. Ediciones, 1996. p. 303. No original: “iEspaña, Madre Nuestra. Hija eterna de la inmortal Roma, heredera dilecta de Atenas la grácil y de Esparta la fuerte...?'. [Tradução do Editor] ${ }^{9}$ SARLO, B. Una modernidad periférica: Buenos Aires 1920 y 1930. Buenos Aires: Nueva Visión, 1999. p. 28. No original: "[en la cultura de mezcla] coexistem elementos defensivos y residuales junto a los programas renovadores (...). La mezcla es uno de los rasgos menos transitorios de la cultura argentina (...)”. [Tradução do Editor]

${ }^{10}$ CANCLINI, Néstor García. Culturas hibridas: estratégias para entrar e sair da modernidade. São Paulo: EDUSP, 2003. p. 206.

${ }^{11}$ La Prensa. In: Substancia, Concepción del Uruguay, no 6, p. 190, novembro de 1951. O jornal La Prensa era um dos principais opositores do governo de Perón. Expropriado, foi entregue à Confederação Geral do Trabalho (CGT), a central sindical que comandou a expressiva sindicalização dos trabalhadores argentinos durante a presidência de Perón. No original: “ $Y a$ hemos dicho alguna vez que, apremiada por el problema fundamental e impostergable de la liberación económica de los sumergidos, la Revolución no pudo pensar mucho en la cultura. Con "La Prensa" popular, el Justicialismo comenzará a probar que la Revolución es también cultura y pensamiento". [Tradução do Editor]

${ }^{12}$ Primer Congreso Provincial de Bibliotecas Populares, s/p. No original: "Nuestra politica social (...) tiende ante todo, a cambiar la concepción materialista de la vida en una exaltación de los valores espirituales. Por eso aspiramos a elevar la cultura social. El Estado argentino no debe regatear esfuerzos ni sacrificios de ninguna clase para extender a todos los ámbitos de la Nación las enseñanzas adecuadas para elevar la cultura de sus habitantes". [Tradução do Editor]

${ }^{13}$ Além de governador de Buenos Aires, Mercante presidiu a Convenção Constituinte que aprovou a Constituição de 1949 e permitiu a Perón disputar a reeleição em 1951. Rompeu com o presidente, pois sua popularidade crescente gerou divisões no partido a respeito da sucessão de Perón.

${ }^{14}$ Primer Congreso Provincial de Bibliotecas Populares, p. 13. Grifo meu. No original: “(...) hacer más estrechos los vínculos que las unen (...) con los organismos oficiales afines, para (...) coordinar mejor la acción que desarrollan en beneficio de la cultura y de la educación del pueblo". [Tradução do Editor]

${ }^{15}$ Leandro H. Gutiérrez e Luis Alberto Romero destacam que a formação da maioria das bibliotecas populares foi uma iniciativa de setores da elite. Contudo, também destacam que as diretorias das bibliotecas eram compostas por membros provenientes de setores populares, que nelas alcançavam reconhecimento e distinção social. As bibliotecas populares, ainda existentes na Argentina, são associaçôes civis autônomas financiadas, total ou parcialmente, pelo Estado. As bibliotecas populares surgiram na Argentina durante o governo do liberal e unitário Domingo Faustino Sarmiento (1868-1874) - Lei 419 de 23 de setembro de 1870 - e se expandiram na década seguinte, a partir da Lei Nacional de Educação Comum. De acordo com um censo promovido pelo governo de Perón, em 1954 existiam 1.676 bibliotecas populares em todo o país. Juntas, possuíam um acervo de 6 milhóes de livros.

${ }^{16}$ Primer Congreso Provincial de Bibliotecas Populares, p. 33. No original: "los que vengan detrás encontrarán un poco más llano el camino que iniciara Sarmiento, y que conduce a una Argentina grande, inmensamente grande”. [Tradução do Editor]

${ }^{17}$ Sarmiento também foi evocado por representantes das bibliotecas, dentre eles Germán García, da Biblioteca Popular "Asociación Bernardino Rivadavia" de Bahia Blanca. "La escuela y la biblioteca se complementan. (...). Fué el problema que Sarmiento vió con claridad consciente de que aprender a leer nada vale si no se utiliza esa habilidad y que la falta de uso hace perderla". (Ibid., p. 76).

${ }^{18}$ Ibid., p. 19. Os "Derechos de la Ancianidad” eram considerados por Perón e Evita como uma de suas principais realizaçōes. O peronismo também utilizou o nome das bibliotecas populares para tentar se apropriar deste legado da tradição liberal argentina. Em 1954, foi publicado pelo Ministério da Educação da Argentina o Guia de Bibliotecas Argentinas. Nesse guia, nota-se como algumas bibliotecas populares tiveram o nome mudado depois da ascensão do peronismo. A Biblioteca Popular Esteban Echeverría, então situada no número 3344 da Aizpurua, tinha sido fundada em 24/2/1924 e, a partir de 1/12/1946 passou a se chamar Biblioteca Popular Eva Perón. Para citar outro exemplo, a Biblioteca Popular da Associação de Fomento de Villa Devoto, então situada no número 3801 da Habana, tinha sido fundada em 2/12/1933 e, em data não fornecida pelo Guia, passou a se chamar Biblioteca Popular Eva Perón. Além disso, bibliotecas surgidas a partir da década de quarenta do século XX adotaram os nomes de Perón e Evita já na fundação, como a Biblioteca Popular Juan D. Perón, então situada no número 2927 da Caseros e fundada em 20/2/1945. Para citar outro exemplo, temos a Biblioteca Popular María Eva Duarte de Perón da CGT, então localizada no cruzamento da Independencia com a Azopardo e fundada em 12/05/1949. No original: "Dia 17: 12 hs.: Almuerzo ofrecido por la Agrupación de Bibliotecas Populares en la Asociación Sarmiento. 16 hs.: Visita al Parque de los Derechos de la Ancianidad sito en la localidad de Pereyra (condicional). 18 hs.: Ofrenda floral al libertador General San Martín". [Tradução do Editor]

${ }^{19}$ Primer Congreso Provincial de Bibliotecas Populares, p. 60. Grifo meu.

${ }^{20}$ Ibid., p. 61. No original: “...la fiscalización en el empleo de los recursos y elementos que provea la Dirección General”. [Tradução do Editor]

${ }^{21}$ Cf. GUTIÉRREZ; ROMERO, op. cit.; KORN, Francis; ROMERO, Luis Alberto (Org.). Buenos Aires/entreguerras: la callada transformación, 1914-1945. Buenos Aires: Alianza Editorial, 2006. 
22 Primer Congreso Provincial de Bibliotecas Populares, p. 61. No original: “El ascenso de categoría podrá ser postergado por la Dirección General, si la biblioteca subvencionada no cumple con un servicio acorde con la importancia de su caudal bibliográfico. La Dirección General, previo estudio de la obra que realice cada biblioteca, podrá hacer aportes especiales a las entidades reconocidas, con resolución debidamente fundada". [Tradução do Editor]

${ }^{23}$ Ibid., p. 22. No original: "Si bien la Subsecretaría de Cultura por intermedio de la Dirección General de Bibliotecas ha tenido a su cargo todo lo relativo a la organización y programación del Congreso, mi presencia en este acto sólo obedece al propósito de presidir la sesión preparatoria hasta constituir las autoridades definitivas que los propios congresales se darán de inmediato". [Tradução do Editor]

${ }^{24}$ Ibid., p. 27. No original: “...dirección y fomento (...) en ningún modo pretende ahogar lo que es expresión auténtica de esos organismos (...). No pretendo fundamentar aqui la sinrazón de un intervencionismo estatal”. [Tradução do Editor]

25 Ibid., p. 56-57. No original: “...representando las Bibliotecas Populares, una creación de la comunidad, deben conservar la libertad de expresión y una actitud de crítica constructiva en relación con todos los problemas de la cultura popular". [Tradução do Editor]

${ }^{26}$ Primer Congreso Provincial de Bibliotecas Populares, p. 30.

${ }^{27}$ Ibid., p. 24.

${ }^{28}$ Ibid., p. 35. No original: "no existe cultura sin orden, y que no es posible alcanzar esa fisonomía espiritual a que aspiramos todos sin esa armonía vital que se enraiza vigorosamente y se nutre en la auténtica esencia nacional'. [Tradução do Editor]

${ }^{29}$ Ibid., p. 29. Grifo meu. No original: “...esa comunión de todos los argentinos, nunca [es] tan fecunda y nunca tan trascendente como cuando se asienta en la cultura del pueblo, cuando se asienta en la verdadera cultura popular". [Tradução do Editor]

${ }^{30}$ BISSO, Andrés. Acción Argentina: un antifascismo nacional en tiempos de guerra mundial. Buenos Aires: Prometeo Libro, 2005.

${ }^{31}$ Em setembro de 1942, foi lançado o número 96 da revista Sur. O número foi dedicado ao Brasil, que tinha recentemente declarado guerra ao Eixo. A Sur publicou uma mensagem lida em um ato de apoio ao Brasil e a Getúlio Vargas, realizado em Buenos Aires, no Luna Park, em 19 de setembro de 1942. No mesmo número, Álvaro de Silva destacou que, ao "declarar la guerra a los agresores, Getúlio no hizo más que obedecer al pueblo”. Grifo meu. (SILVA, Álvaro de. Luz y black-out en Río. In: Sur, Buenos Aires, n 96, p. 97, setembro de 1942). Para traçar um paralelo e pressionar o governo argentino a também "obedecer ao povo", no ato do Luna Park, os participantes se colocaram como a totalidade do povo argentino, que expressava "al pueblo brasileño su inequivoca solidariedad" (Mensaje de los argentinos al presidente del Brasil. In: Sur, Buenos Aires, $\mathrm{n}^{\circ}$ 96, p. 94, setembro de 1942).

32 Primer Congreso Provincial de Bibliotecas Populares, p. 71-72. No original: “... libros amenos, sanos, con episodios de la vida nacional que le enseñen a querer a su tierra y den una visión clara de su patria, todo en armonía con sus gustos y necesidades". [Tradução do Editor]

${ }^{33}$ Ibid., p. 88.

${ }^{34}$ Ibid., p. 31. No original: "Nuestro intelectualismo padece de lo exótico, olvidando lo vernáculo. Hay una ciencia argentina, una literatura argentina, una historia argentina, un arte argentino. Las bibliotecas populares deben actuar en función de argentinidad. No es preciso desconocer los enormes valores de la genialidad extranjera para encarecer la importancia de nuestros propios valores". [Tradução do Editor]

${ }^{35}$ Ibid., p. 41.

${ }^{36}$ Ibid., p. 80. Grifos meus. No original: "No me refiero expresamente a la adquisición de obras de escritores o temas argentinos, porque es obvio que en cualquier plan elaborado con inteligencia ha de entrar en el primer plano la posesión de libros que estudien el país y producciones de quienes están más cerca de nosotros". [Tradução do Editor]

${ }^{37}$ Ibid., p. 83.

${ }^{38}$ Ibid., p. 26.

${ }^{39}$ Ibid., p. 84 . Grifo meu.

${ }^{40}$ Ibid., p. 85.

${ }^{41}$ Ibid., p. 113. No original; “...obras de fisiología, libros que no llenen una finalidad de texto, literatura pornográfica, con escenas inconvenientes a la moral, etc.”. [Tradução do Editor]

${ }^{42}$ Ibid., p. 113.

${ }^{43}$ Ibid., p. 114.

${ }^{44}$ A revista Sur (1931-1991) destacava o passado político de Perón, ligado ao GOU, Grupo de Oficiais Unidos, composto por militares antiliberais e nacionalistas. Além disso, criticava o intervencionismo e as propostas nacionalistas do governo na esfera cultural.

${ }^{45}$ Sobre a revista Sur: KING, John. Sur: estudio de la revista argentina y de su papel en el desarrollo de una cultura (1931-1970). Cidade do México: Fondo de Cultura Económica, 1989; PASTERNAC, Nora. Sur, una revista en la tormenta: los años de 
formación, 1931-1944. Buenos Aires: Paradiso, 2002; SITMAN, Rosalie. Victoria Ocampo y Sur: entre Europa y America. Buenos Aires: Lumiere, 2003.

46 Seis anos de governos considerados nacionalistas, pois, em 1943, o GOU liderou um golpe de Estado na Argentina. No governo de Edelmiro Farrell (1944-1946), terceiro presidente a assumir após o golpe, Perón tornou-se vice-presidente, Ministro da Guerra e Secretário do Trabalho.

${ }^{47}$ Primer Congreso Provincial de Bibliotecas Populares, p. 116.

${ }^{48}$ Ibid., p. 30. Grifos meus. No original: "El concepto de guardador de libros ha sido substituido por un nuevo sentido de cooperación social, y, en este aspecto, son las bibliotecas populares las que, desde hace tiempo, encaminan sus pasos en procura de ese acercamiento del hombre del pueblo al libro de ciencia, a la divagación filosófica, a la magia del arte”. [Tradução do Editor]

${ }^{49}$ Ibid., p. 90.

${ }^{50}$ Ibid., p. 78. No original: "Una biblioteca pequeña, de pueblo o barrio, no ha de dejarse conquistar por los cantos de sirena de obras lujosas o colecciones que no sirven alli ni para exhibición”. [Tradução do Editor]

\section{Referências bibliográficas}

BISSO, Andrés. Acción Argentina: un antifascismo nacional en tiempos de guerra mundial. Buenos Aires: Prometeo Libros, 2005.

CAPELATO, Maria Helena Rolim. Multidões em cena: propaganda política no varguismo e no peronismo. Campinas: Papirus, 1998.

CANCLINI, Néstor García. Culturas híbridas: estratégias para entrar e sair da modernidade. São Paulo: EDUSP, 2003.

CERTEAU, M. de. A cultura no plural. Campinas: Papirus, 2003.

CIRIA, Alberto. Politica y cultura popular: la Argentina peronista (1946-1955). Buenos Aires: Ediciones de la Flor, 1983.

ELOY MARTÍNEZ, Tomás. Santa Evita. Tradução Sérgio Molina. São Paulo: Companhia das Letras, 1997.

FIORUCCI, Flavia. ¿Aliados o enemigos? Los intelectuales en los gobiernos de Vargas y Perón. In: Estudios Interdisciplinarios de America Latina y el Caribe, v. 15, nº 2, jul.-dez. 2004. Disponível em: <http://www.tau.ac.il/eial/ XV_2/fiorucci.html>. Acesso em: 2 maio 2005.

FIORUCCI, Flavia. Reflexiones sobre la gestión cultural bajo el peronismo. In: Nuevo Mundo Nuevos Mundos, 10 de fevereiro de 2008. Disponível em <http://nuevomundo.revues.org/index24372.html $>$. Acesso em: 9 julho 2008.

GERMANI, Gino. Política e sociedade numa época de transição: da sociedade tradicional à sociedade de massas. São Paulo: Mestre Jou, 1973.

Guia de bibliotecas argentinas. Ministerio de Educación de la Nación. Dirección General de Cultura. Comisión Protectora de Bibliotecas Populares. Buenos Aires, 1954.

GUTIÉRREZ, Leandro; ROMERO, Luis Alberto. Sectores populares, cultura y política: Buenos Aires en la entreguerra. Buenos Aires: Siglo XXI, 2007.

JAMES, Daniel. 17 y 18 de octubre de 1945: el peronismo, la protesta de masas y la clase obrera argentina. Desarrollo Económico, Buenos Aires, v. 27, n 107, outubro-dezembro de 1987.

JAMES, Daniel. Ideologia popular e resistência de classe: o peronismo e a classe operária (1955-1960). Revista Brasileira de História, São Paulo, v. 5, nº 10, março-agosto de 1985.

JAMES, Daniel. Racionalización y respuesta de la clase obrera: contexto y limitaciones de la actividad gremial en la Argentina. Desarrollo Económico, Buenos Aires, v. 21, no 83, outubro-dezembro de 1981.

JAMES, Daniel. Resistencia e integración: el peronismo y la clase trabajadora argentina, 1946-1976. Buenos Aires: Siglo XXI Editores, 2005.

KING, John. Sur: estudio de la revista argentina y de su papel en el desarrollo de una cultura (1931-1970). Cidade do México: Fondo de Cultura Económica, 1989.

KORN, Francis; ROMERO, Luis Alberto (Org.). Buenos Aires/entreguerras: la callada transformación, 19141945. Buenos Aires: Alianza Editorial, 2006.

La Prensa. In: Substancia, Concepción del Uruguay, nº 6, novembro de 1951. 
Mensaje de los argentinos al presidente del Brasil. In: Sur, Buenos Aires, n 96, setembro de 1942.

MURMIS, Miguel; PORTANTIERO, Juan Carlos. Estudos sobre as origens do peronismo. São Paulo: Brasiliense, 1973.

PASTERNAC, Nora. Sur, una revista en la tormenta: los años de formación, 1931-1944. Buenos Aires: Paradiso, 2002.

PERÓN, E. El testamento. Cuadernos de Crisis, Buenos Aires, $\mathrm{n}^{\circ}$ 7, s./d.

PERÓN, E. Por qué soy peronista y las fuerzas espirituales del peronismo. Buenos Aires: C. S. Ediciones, 1996.

PERÓN, Juan Domingo. Doctrina peronista. Buenos Aires: C. S. Ediciones, 1996.

PLOTKIN, Mariano. Mañana es San Perón: propaganda, rituales políticos y educación en el régimen peronista (1946-55). Buenos Aires: Ariel, 1993.

Primer congreso provincial de bibliotecas populares. La Plata: Provincia de Buenos Aires; Ministerio de Educación; Dirección General de Bibliotecas, 1951.

SARLO, B. Una modernidad periférica: Buenos Aires 1920 y 1930. Buenos Aires: Nueva Visión, 1999.

SILVA, Álvaro de. Luz y black-out en Río. In: Sur, Buenos Aires, nº 96, setembro de 1942.

SITMAN, Rosalie. Victoria Ocampo y Sur: entre Europa y America. Buenos Aires: Lumiere, 2003.

\section{RESUMO}

O governo do presidente argentino Juan Domingo Perón (1946-1955) desenvolveu uma política cultural voltada aos setores populares. Para o peronismo, a questão político-social e a cultural eram indissociáveis. O Primeiro Congresso de Bibliotecas Populares da Provincia de Buenos Aires (1949) foi uma das iniciativas dessa politica cultural peronista. Entretanto, ela foi marcada por divergências, inclusive internas, quanto à centralidade do nacionalismo, à formação que deveria ser dada aos setores populares e ao legado da tradição liberal argentina. Palavras-chave: Argentina; peronismo; intelectuais; cultura; setores populares.

\section{ABSTRACT}

The government of the Argentine president Juan Domingo Peron (1946-1955) has developed a cultural policy directed to the popular sectors. For Peronism, the political, social and cultural issues were inseparable. The First Congress of Popular Libraries of the Province of Buenos Aires (1949) was one of the initiatives of this Peronist cultural policy. However, this policy was marked by divergence, including internal divergences, about the centrality of nationalism, the training that the population at large should receive, and the legacy of the Argentine liberal tradition.

Keywords: Argentine; Peronism; intellectuals; culture; popular sectors. 